\title{
Efficiency Status of the Elective Non-Cardiac Surgery Operating Rooms of the Department of Surgery of the Philippine General Hospital
}

\author{
Marie Carmela M. Lapitan, ${ }^{1,2,3}$ Brian S. Buckley, ${ }^{1}$ Donna D. Abalajon, ${ }^{1}$ \\ Patricia Lorna O. Cruz ${ }^{4}$ and Maria Eliza M. Raymundo ${ }^{1,3,5}$ \\ ${ }^{1}$ Department of Surgery, College of Medicine and Philippine General Hospital, University of the Philippines Manila \\ ${ }^{2}$ Institute of Clinical Epidemiology, National Institutes of Health, University of the Philippines Manila \\ ${ }^{3}$ Department of Surgery, Uniformed Services University of the Health Sciences, Maryland, USA \\ ${ }^{4}$ Department of Anesthesia, College of Medicine and Philippine General Hospital, University of the Philippines Manila \\ ${ }^{5}$ Institute of Molecular Biology and Biotechnology, National Institutes of Health, University of the Philippines Manila
}

\begin{abstract}
Introduction. The operating room (OR) is one of the most costintensive units of any health care facility. Hence, OR efficiency has become a priority of many institutions. Delays in the OR lead to poor cost effectiveness and cause frustration both to patients and to OR staff.
\end{abstract}

Objectives. This study aims to describe the efficiency of the Philippine General Hospital Department of Surgery elective noncardiac surgery operating room services using established parameters and identify causes of delays.

Methods. A cross-sectional survey was conducted of randomly selected elective cases from October 2011 to January 2012. A framework of elements in the OR process and timing milestones were defined. These times were recorded during the OR process. Mean and median observed times for these elements were calculated and compared with target times based on previous research. Causes of delay were recorded.

Results. Once anesthesia was started, target times for most parameters were met in the majority of cases. Delays were most notable between patient entry to the OR complex and start of anesthesia, particularly for first cases. Only 3.9\% of cases started at or before the scheduled time; $49.7 \%$ of cases started more than one hour late. $54.3 \%$ of late starts were caused by surgeons not being in the OR complex on time. Errors in estimating case duration were commonplace: more than one third of cases took more than an hour longer or shorter than estimated. While the mean delay in start for first cases was nearly one hour, the mean delay for second and third cases was nearly two hours.

Corresponding author: Marie Carmela M. Lapitan, MD

Department of Surgery

Philippine General Hospital

University of the Philippines Manila

Taft Avenue, Ermita, Manila 1000 Philippines

Telephone: +632 5255453

Email: melalapitan@gmail.com
Conclusions. The majority of cases start late. The most common cause of delay is the surgeon's tardiness. Considerable discrepancy between the predicted and actual case duration was also observed.

Key Words: operating room efficiency, OR delays, efficiency parameters, case duration error, surgery, Philippines

\section{Introduction}

Increasing attention is being paid to cost effectiveness in health care, and operating room (OR) efficiency has become a priority of many institutions in both developed and developing countries. The operating room is one of the most cost-intensive units of a health care facility, given the amount of personnel and equipment present, and the sustained intensity of clinical activity taking place. Efficiency is considered crucial for increased profitability by for-profit hospitals, while for non-profit establishments, better efficiency allows more work to be done for the same cost. ${ }^{1}$

Delays in the OR do not only lead to poor cost effectiveness, but also cause significant frustration both to patients and to OR staff. Prolonged waiting time may diminish patient satisfaction. Surgeons and anesthesiologists may become frustrated if their scheduled procedures do not start on time. Overtime may have to be paid to nurses and OR personnel if cases go beyond the expected operative schedule, resulting in additional costs to the health care facility. ${ }^{2}$ Delays in the OR can be a source of interpersonal conflict between surgeons, anesthesiologists, nurses, and other OR personnel. Deferral of cases can also mean longer preoperative hospital stay, slower patient turnover, additional patient expenses and inefficient use of hospital funds. Many institutions are studying OR efficiency in order to maximize productivity and minimize wastage of hospital resources.

The Philippine General Hospital (PGH) is the national university hospital and caters to patients from all over the country, including both paying and charity cases. The Department of Surgery performs an average of 3,700 charity and 2,700 paying cases of elective major non-cardiac 
surgeries annually. Charity cases are performed by resident trainees in surgery and anesthesia who are primarily based in the hospital, while the private cases are performed by consultant surgeons and anesthesiologists who work in several hospitals. On the average per month, 25 operating rooms manned by 28 eight-hour shifts of OR nurses are available for use by the charity service. On the other hand, 22 operating rooms are assigned to the private cases, manned by 48 eight-hour OR nurses' shifts. Like most operating suites, those in $\mathrm{PGH}$ experience capacity constraints due to the growing patient volume, limited manpower, inadequate resources, and fixed physical space. ${ }^{3}$ This study aims to describe the efficiency of the PGH Department of Surgery elective operating room services using established parameters and identify causes of delays.

\section{Methods}

A cross sectional survey was conducted of elective operative cases under the Department of Surgery, randomly selected from cases entered into the final operating room schedule of the PGH-OR Complex from 15 October 2011 to 31 January 2012. Data were collected for operations in both the charity and the private services. The study excluded cases done by other surgical departments, i.e. Otorhinolaryngology, Orthopedics, Neurosurgery, and Obstetrics and Gynecology. Thoracocardiovascular service operations were excluded as well, as they were performed in that service's own OR complex, with a separate surgical, anesthesia, and nursing staff. Also excluded from this study were emergency and outpatient operations, elective surgeries scheduled after the working day has started and canceled cases.

A framework of elements that constitute the OR process for each case, from patient entry to the OR complex to patient exit from OR (Figure 1) was determined before the study. Each element was assigned a target time, based on previous research by Overdyk and collegues. ${ }^{4}$ The following timing milestones were noted for each operation: time of patient arrival at OR complex and into the operating room, anesthesia preparation start time, anesthesia start time, anesthesia end time, surgical preparation start and end times, procedure start and end times, time the patient was declared ready for transfer out of the OR, and time the patient was brought out of the OR. Based on these milestones, the following time periods were computed: patient wait time, entry lag, anesthesia preparation and standby time, anesthesia induction and handover time, surgical preparation time, time out prior to surgery, surgery duration, wake up time, and exit lag (Table 1). These time periods constituted the OR efficiency parameters used in the analysis. If a case was unable to meet the target time established for any of the efficiency parameters, the causes of the delay were recorded. Table 2 presents the different classification of the causes of delays. ${ }^{4}$
Table 1. Operational definition of OR efficiency parameters (time periods computed based on the operating room milestones)

\begin{tabular}{|c|c|}
\hline $\begin{array}{c}\text { Time Period / } \\
\text { Efficiency Parameter }\end{array}$ & Definition \\
\hline Patient Wait Time & $\begin{array}{l}\text { Time from patient entry into the OR } \\
\text { complex to start of anesthesia preparation }\end{array}$ \\
\hline Entry Lag & $\begin{array}{l}\text { Time from patient entry into OR to start of } \\
\text { anesthesia preparation }\end{array}$ \\
\hline $\begin{array}{l}\text { Anesthesia Preparation / } \\
\text { Stand by Time }\end{array}$ & $\begin{array}{l}\text { Time from when anesthesiologist receives } \\
\text { the patient at the OR until the start of } \\
\text { anesthesia induction }\end{array}$ \\
\hline $\begin{array}{l}\text { Anesthesia Induction and } \\
\text { Handover Time }\end{array}$ & $\begin{array}{l}\text { Time spent on administration of anesthesia; } \\
\text { time from start of anesthesia induction to } \\
\text { surgical prep start time }\end{array}$ \\
\hline $\begin{array}{l}\text { Surgical Preparation } \\
\text { Time }\end{array}$ & $\begin{array}{l}\text { Time spent for prepping and positioning of } \\
\text { the patient for surgery; Time from surgical } \\
\text { prep start time to surgical prep end time }\end{array}$ \\
\hline Surgery TIme Out & $\begin{array}{l}\text { Interval from end of surgical prep to start of } \\
\text { surgery }\end{array}$ \\
\hline Surgery Duration & $\begin{array}{l}\text { Time interval from procedure start time to } \\
\text { procedure end time }\end{array}$ \\
\hline Wake Up Time & $\begin{array}{l}\text { Time interval from end of surgery to } \\
\text { complete emergence from anesthesia }\end{array}$ \\
\hline Exit Lag & $\begin{array}{l}\text { Interval from time of complete emergence } \\
\text { from anesthesia to exit from OR }\end{array}$ \\
\hline Difference in Start Time & $\begin{array}{l}\text { Difference between actual and predicted } \\
\text { procedure start time }\end{array}$ \\
\hline Case Duration Error & $\begin{array}{l}\text { Difference between predicted case duration } \\
\text { and surgery duration (actual operative } \\
\text { time) }\end{array}$ \\
\hline
\end{tabular}

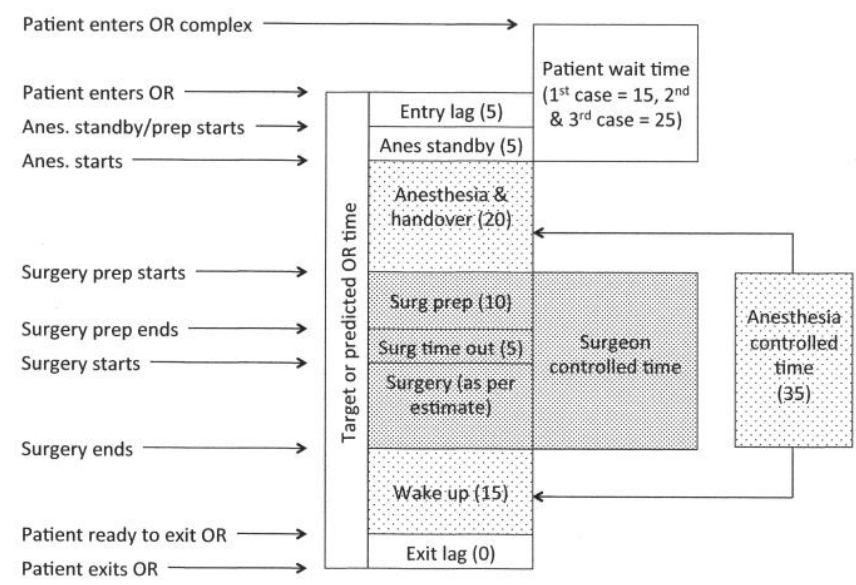

Figure 1. Flowchart of operating room events and milestones (figures in parenthesis indicate target time in minutes) 
Table 2. Classification of causes of delays

\begin{tabular}{ll}
\hline Preoperative & Patient transport delay \\
& Work up delay \\
& Missing/inadequate consent \\
& Inadequate surgical workup \\
& Inadequate anesthesia workup \\
Preinduction & Surgical equipment delay \\
& Anesthesia equipment delay \\
& Housekeeping turnover delay \\
& Line placement difficulty \\
& Nursing set up delay \\
& X-ray positioning \\
& Difficult airway management \\
& Difficult regional placement \\
& Anesthesia attending starting other case \\
& Anesthesiologist not in OR complex \\
& Failure of anesthesia technique \\
& Anesthesia adverse reaction \\
& Radiology technician not available \\
& Attending surgeon not in OR complex \\
& Attending surgeon in different OR \\
Surgical equipment delay / No supply available & Lab result delay (includes frozen section) \\
Intraoperative consultation \\
Delayed transport of blood products \\
No stretcher bed available \\
Institutional worker not available \\
No PACU bed available \\
No SICU bed available \\
Prolonged emergence \\
Case canceled or case moved \\
Power interruption \\
Others \\
\hline
\end{tabular}

For each case, data were collected regarding the planned procedure, actual procedure performed, predicted case duration, division/specialty and service (charity vs. private) performing the operation, surgeon, anesthesiologist, type of anesthesia performed, and case sequence.

Prior to study data collection, a pilot test phase of 6 weeks was conducted during which surgeons, anesthesiologists and operating room nurses were oriented and coached on proper recording of the OR efficiency parameters and completion of the data collection sheets.
Based on observations made during the pilot testing, the format of the data collection sheets was finalized. During actual data collection, data forms were completed by different members of the operating room staff. A research assistant specifically trained in the proper completion and audit of the data collection sheets was also available in the OR at all times to assist in the form completion as well as independently to observe, measure and record the different OR efficiency parameters. A cross-checking and consolidation of the different data collection forms completed by the different $\mathrm{OR}$ team members for each case was done.

Analysis considered the dataset as a whole, by private and charity services, and by case sequence. The mean and median times for the measured OR efficiency parameters were calculated.

The study protocol was reviewed and approved by the University of the Philippines Manila Research Ethics Board.

\section{Results}

Data was collected from 545 elective cases representing $59 \%$ of cases performed during the data collection period (49\% of Charity and $92 \%$ of Private operations). The final analysis included 539 cases, after exclusion of canceled cases and those with inadequate data for proper determination of a majority of the milestones. The surgeries were performed by 78 different primary surgeons and attended by 66 different anesthesiologists.

Analysis considered efficiency during the OR process for each case using the framework of procedural elements and target times. Mean and median observed times for the parameters evaluated and the percentage of cases completed within target times are presented in Table 3.

The period during which delays were most notable was the patient wait time - the time between patient entry to the OR complex and start of anesthesia. Delays during this time were most notable for first cases, when patient wait time exceeded the target time by a mean of 41 minutes. For

Table 3. Mean and median times of measured efficiency parameters and number (\%) of cases exceeding target time.

\begin{tabular}{|c|c|c|c|c|c|c|c|c|}
\hline & $\mathbf{N}$ & Target & $\begin{array}{c}\text { Mean } \\
\text { (SD) }\end{array}$ & $\begin{array}{c}\text { Difference between } \\
\text { mean \& target }\end{array}$ & Median & $\begin{array}{l}\text { Difference between } \\
\text { median \& target }\end{array}$ & Range & $\begin{array}{c}\text { Percentage of Cases } \\
\text { within Target }\end{array}$ \\
\hline Patient wait time ( $1^{\text {st }}$ cases) & 264 & 15 & $56(33)$ & +41 & 51 & +36 & 2,209 & 6.8 \\
\hline Patient wait time ( $2^{\text {nd }}$ cases) & 181 & 25 & $41(33)$ & +16 & 32 & +7 & 0,320 & 38.7 \\
\hline Patient wait time ( $3^{\text {rd }}$ cases) & 62 & 25 & $42(37)$ & +17 & 30 & +5 & 8,182 & 45.2 \\
\hline Entry lag & 500 & 5 & $22(27)$ & +17 & 10 & +5 & 0,170 & 35.2 \\
\hline Anesthesia standby time & 513 & 5 & $19(24)$ & +14 & 10 & +5 & 0,260 & 35.1 \\
\hline $\begin{array}{l}\text { Anesthesia induction \& } \\
\text { handover time }\end{array}$ & 516 & 20 & $15(14)$ & -5 & 10 & -10 & 0,110 & 77.7 \\
\hline Surgery prep time & 518 & 10 & $6(5)$ & -4 & 5 & -5 & 0,45 & 69.1 \\
\hline Surgery time out & 518 & 5 & $6(7)$ & +1 & 5 & 0 & 0,58 & 69.1 \\
\hline Wake up time & 526 & 15 & $13(13)$ & -2 & 10 & -5 & 0,125 & 77.9 \\
\hline Exit lag & 526 & 0 & $6(8)$ & +6 & 5 & +5 & 0,125 & 11.0 \\
\hline $\begin{array}{l}\text { Difference: actual versus } \\
\text { predicted case/surgery duration }\end{array}$ & 531 & 0 & $-5(68)$ & -5 & -15 & -15 & $-322,480$ & \\
\hline $\begin{array}{l}\text { Difference: actual versus } \\
\text { predicted total OR duration }\end{array}$ & 519 & 0 & 37 (131) & +37 & 10 & 10 & $-295,1008$ & \\
\hline
\end{tabular}


second and third cases, the target was exceeded by means of 16 and 17 minutes, respectively.

Only $3.9 \%$ of cases started at or before the scheduled time, 11.5\% within 20 minutes after the scheduled time and $49.7 \%$ of cases started more than one hour after the scheduled time. Overall the mean delay between scheduled and actual start time was 84.4 minutes (SD 77.6) and the median 60 minutes. Mean delay time for first surgeries was 55.2 minutes (SD 48.6). Mean delays for second and third cases were 114.8 minutes (SD 91.0) and 117.0 minutes (SD 86.8), respectively. There was little difference between private and charity cases (Figure 2).

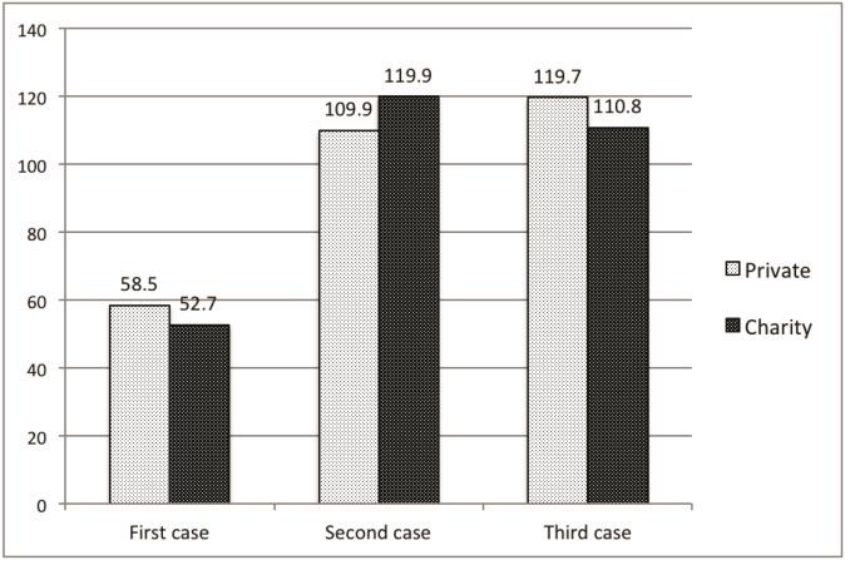

Figure 2. Mean difference between scheduled and actual start times by case sequence number and private versus charity

Unlike second and third cases, first cases are not affected by a "knock on" effect of delays in previous surgeries and should start on time. The reason for the delayed start was recorded for 141 first cases. Over half the cases were delayed because the surgeon was not in the OR complex $(76 / 141,54.3 \%)$. Other causes were the absence of the anesthesiologist (13/141, 9.2\%) and delays associated with patient transport and waiting for blood products $(18 / 141,12.8 \%)$, and surgical $(12 / 141,8.5 \%)$ and anesthetic equipment problems (11/141, 7.8\%). Nursing delays only accounted for $3 \%$ of the delays (7/141).

Once anesthesia had commenced, the target times for all parameters, apart from exit lag, were met by the majority of cases. Anesthesia and handover time and wake up time were within targets for more than three quarters of all cases. Surgical preparation time and surgery time out were within target times in more than two-thirds of cases.

Case duration error - the difference between predicted and actual duration of the surgical procedure itself - both affects and reflects how well a team plans operations and allocates time. Overall, cases finished an average of 5 minutes earlier than the predicted case duration. However, case duration error accounted for a mean of $54.7 \%$ of the overall difference between predicted and actual total OR time. Figure 3 illustrates case duration error, with cases stratified into forty-minute time bands that represent degrees of variance from the estimate. The central time band includes $30.1 \%$ of cases that were completed within twenty minutes either shorter or longer than the estimated time. $13.5 \%$ of cases lasted 21-60 minutes longer than predicted, and $10.7 \%$ more than an hour longer. $33.1 \%$ finished $21-60$ minutes before the estimated time, and $12.6 \%$ more than an hour before. The error between predicted and actual total OR time is illustrated in Figure 4. This analysis combines case duration error with variance from target times for all other elements of the OR process, and the number of cases overrunning predicted times by more than an hour increases to $26.3 \%$ while the numbers finishing more than an hour early decreases slightly to $10 \%$.

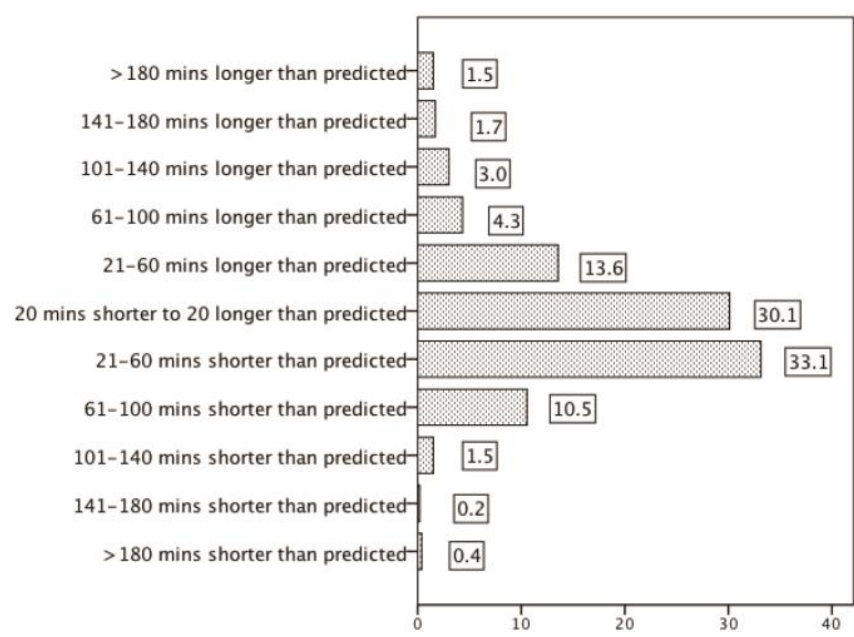

Figure 3. Cases classified by Case Duration Error (figures in boxes are percentages)

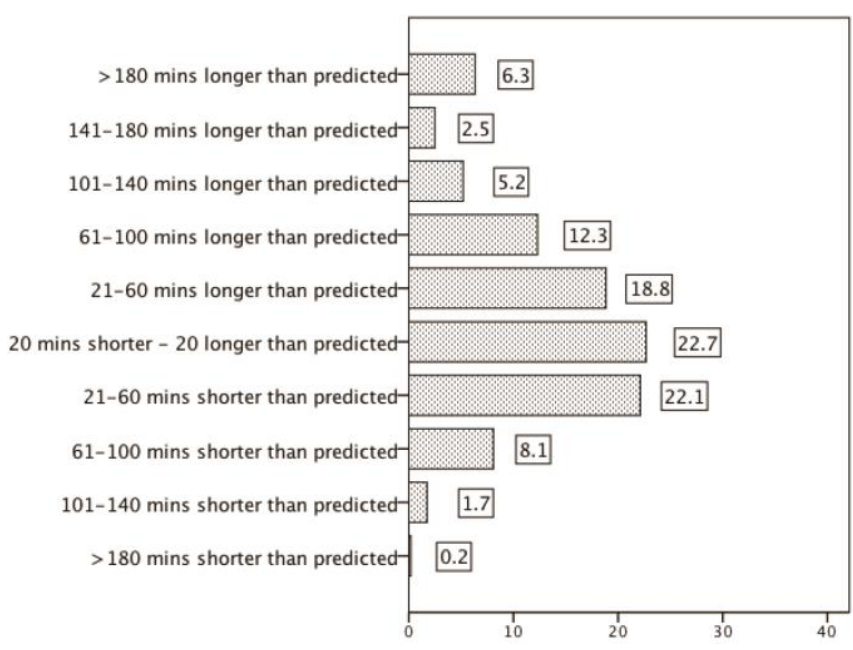

Figure 4. Cases classified by error between predicted and actual total OR time 


\section{Discussion}

Delays and poor time management in the perioperative period disrupt patient flow, undermine efficient use of time and facilities, increase anxiety in patients and their relatives, and cause significant frustration for surgeons and the entire OR staff. In this study, the factors that most seriously undermined the efficient use of OR time and facilities were associated with failures to start cases on time and poor estimation of surgery duration. Other elements in the OR process associated with anesthesia and patient preparation in the OR were completed within target times in the majority of cases.

The most serious delays in terms of frequency and scale were associated with failures to start at the scheduled times: only $11.5 \%$ of cases started within 20 minutes after the scheduled time and $49.7 \%$ started over an hour late. This means that over 3,000 of the approximately 3,500 elective surgeries conducted by the Department involved in the study each year may similarly be delayed by 20 minutes and 1,750 by an hour.

Although the absence of anesthesiologists and delays associated with patient transport, blood products, and equipment problems contributed to delays in starting many cases, more than half of delayed starts resulted from the absence of surgeons. The failure of surgeons and anesthesiologists to be in the OR complex on time was also the most common reason for delayed surgery starts in a 1998 study conducted in the USA. ${ }^{4}$

Starting on time has been seen to result in less rush in OR working practices throughout the day, ${ }^{1}$ thus decreasing the possibility of errors occurring and increasing the hospital's capacity to provide a safer environment for the patient. ${ }^{5}$ Research has highlighted the economic benefits of avoiding delayed starts, especially in institutions with OR suites operating for more than 8 hours per day. The benefits can be savings in overtime payments, overhead expenses or in time taken off by staff in lieu of extra hours worked. ${ }^{6,7}$ In hospitals like $\mathrm{PGH}$, where resources are limited, increasing efficiency in the operating suite has the potential to translate into financial savings, which in turn may be used to hire additional personnel and to acquire much needed equipment.

Failure to properly estimate case duration was identified as a significant factor in reducing OR efficiency: nearly a quarter of all surgical procedures in this study either lasted more than an hour longer than estimated or took more than an hour less than estimated. Both over- and under-estimating have implications for OR efficiency. ${ }^{2}$ If a case overruns its estimated duration, subsequent cases are delayed. If a case finishes early, this leads to inefficient use of staff and facilities. An audit of elective surgical cases in an academic medical center in the USA has also shown that error in estimation of case duration was one of the most important contributory factors for OR delays, undermines operative planning and results in inefficient allocation of time, manpower and resources. ${ }^{2}$ An analysis of the OR times of more than 20,000 outpatient surgical cases estimated the direct cost of inaccurate forecasts to exceed $\$ 1$ million annually for a moderate sized facility. ${ }^{8}$

In this study, when case duration error is combined with variance from target times for all other elements of the OR process, the total OR time for more than one third of cases was either an hour greater or an hour less than estimated. Similar to the findings in this study, a report on an approach in improving surgical start time in a Canadian hospital identified surgeon and anesthesiologist availability as the most common cause of delays. Other reasons cited included poor patient preparation, inadequate or missing consent or insufficient surgical or anesthesia work up, factors that were also observed in this study. ${ }^{1}$ A prospective study of 1531 elective neurosurgical cases showed equipment failure or delay in equipment set-up as the most common cause of perioperative delays. ${ }^{6}$ In our study, equipment-associated interruptions (surgical and anesthesia equipment) accounted for only $16 \%$ of the documented delays.

\section{Implications for practice}

Strategies are needed to address these problems and at the very least reduce avoidable delays. Delayed starts and delays during the OR process can reduce the number of cases that may be done in an OR with limited operating hours, and can result in deferral and cancellation of cases. Failure to accommodate more cases can mean slower turnover in hospital admissions, extending the inefficiency from the OR to the rest of the hospital operations.

Unlike cases later in the day, first cases are unaffected by preceding cases so that there is no uncertainty about start times and principal personnel should be in the OR on time. That $54.3 \%$ of late starts for first cases were caused by the absence of surgeons and $9.2 \%$ by the absence of anesthesiologists is a finding that should be taken very seriously both by those professions and by hospital administrators. This study has highlighted the scale of the problem and ideally professionals - surgeons especially should take responsibility for ensuring that their own timekeeping does not undermine hospital efficiency and ultimately patient care.

Failing that, hospital administrators should consider strategies to address the problem. One Canadian hospital instituted a mandatory "huddle" between surgeon, anesthesiologist and nurses to discuss the scheduled case 25 minutes prior to schedule. ${ }^{1}$ Another way to address physician lateness in the OR is by monitoring their arrival time and providing them regular feedback and by imposing appropriate measures or penalties on those who are habitually late. For example, surgeons noted to regularly arrive late in the OR to start first cases based on this 
monitoring system, should not be allowed to have their operations scheduled as first cases. This practice of monitoring and feedback has been shown to decrease firstcase tardiness by at least $13 \%$ within two weeks of implementation; with overall improvement in on-time starts from $24 \%$ to $80 \% .^{8}$

An OR manager who has a general oversight of the entire OR complex could also optimize utilization of facilities and personnel by opening up extra operating rooms if extra personnel become available, or transferring cases to another room whose operations finished early or got canceled. This form of flexibility and adaptability has been shown to be important components of achieving efficiency in the operating room complex.5,9 Several studies have reported methods to improve the efficiency of the OR. A data modeling study using survey information from a German hospital showed that the appointment of an OR manager to coordinate scheduling of different members of the OR staff reduced delays in first case starts. ${ }^{10}$

Proper discussion and planning of cases in advance, if necessary supplemented by checklists, may prevent delays caused by inadequate work up or consent problems.

The information on the actual case durations of the common procedures provided by this study and by continued monitoring and evaluation of the OR efficiency parameters can be utilized to guide surgeons and the OR staff in formulating the predicted case durations for procedures being scheduled. This will improve planning and rationalize the distribution and sequencing of cases in the different operating rooms.

\section{Strengths and limitations of the study}

Evaluations of time management in surgery are difficult to conduct and relatively rare. This is the only Philippine study of its kind to be published. It provides a useful insight into causes of poor OR time and resource use, arguably of particular importance in a resource-poor government hospital setting. A similar study conducted in a private hospital may provide useful comparative data.

However, some limitations must be acknowledged. The study has not considered other procedural elements that may affect time management, such as surgery and anesthesia types and patient characteristics. Further research is suggested that can consider the effect on case duration error of such factors as surgical and anesthesia types and complexity, patient characteristics and positioning, and case sequencing.

Although little difference was observed, the mobility of different kinds of staff may have the potential to cause more delays in private than in charity cases. With regards charity cases, surgical residents work only within the Department of Surgery's operating rooms and for the period covered by the study, the nurses and anesthesiology residents were specifically assigned to one operating room of the
Department of Surgery only. Consultant surgeons and anesthesiologists, on the other hand, may be delayed by attending cases in other hospitals and departments. Data on this factor were not collected.

The government hospital setting may mean that the findings of the study may not be generalizable to other types of hospitals. Likewise, the findings may not be generalizable to other surgical areas whose case mix may tend towards fewer but longer surgeries, or more but shorter surgeries.

\section{Conclusion}

This study presented the efficiency status of the elective non-cardiac surgery operating rooms under the Department of Surgery of the Philippine General Hospital using a framework of milestones and time periods of the OR process. It demonstrated that a significant number of cases fail to start on time and the most common cause of the delay is the surgeon's tardiness. Considerable discrepancy between the predicted and actual case duration is also observed.

\section{Acknowledgments}

The authors would like to thank Ms. Julie Mangahis, RN, Mr. Michael Mercado, RN and Ms. Glycerine dela Rosa-Manalo for their assistance in the collection and collation of the data.

This study was partially funded by a research grant from the National Institutes of Health - University of the Philippines Manila.

\section{References}

1. Wright JG, Roche A, Khoury AE. Improving on-time surgical starts in an operating room. Can J Surg. 2010; 53(3):167-70.

2. Wachtel RE, Dexter F. Influence of the operating room schedule on tardiness from scheduled start times. Anesth Analg. 2009; 108(6):1889901.

3. Sokal SM, Craft DL, Chang Y, Sandberg WS, Berger DL. Maximizing operating room and recovery room capacity in an era of constrained resources. Arch Surg. 2006; 141(4):389-93.

4. Overdyk FJ, Harvey SC, Fishman RL, Shippey F. Successful strategies for improving operating room efficiency at academic institutions. Anesth Analg. 1998; 86(4):896-906.

5. Cima RR, Brown MJ, Hebl JR, et al. Use of lean and six sigma methodology to improve OR efficiency in a high-volume, tertiary care academic medical center. J Am Coll Surg. 2011; 213(1):83-92.

6. Wong J, Khu KJ, Kaderali Z, Bernstein M. Delays in the operating room: signs of an imperfect system. Can J Surg. 2010; 53(3):189-95.

7. Dexter F, Epstein RH. Typical savings from each minute reduction in tardy first case of the day starts. Anesth Analg. 2009; 108(4):1262-7.

8. Dexter F, Macario A. Changing allocations of operating room time from a system based on historical utilization to one where the aim is to schedule as many surgical cases as possible. Anesth Analg. 2002 May; 94(5) 1272-9.

9. Fezza M, Palermo GB. Simple solutions for reducing first-procedure delays. AORN J. 2011; 93(4):450-4.

10. Ernst C, Szczesny A, Soderstrom N, Siegmund F, Schleppers A. Success of commonly used operating room management tools in reducing tardiness of first case of the day starts: evidence from German hospitals. Anesth Analg. 2012 Sep; 115(3): 671-7. 